\title{
Erratum to: Proton pump inhibitors as risk factor for metabolic syndrome and hepatic steatosis in coeliac disease patients on gluten-free diet
}

Nicola Imperatore ${ }^{1}$ (D) Raffaella Tortora $^{1,2} \cdot$ Anna Testa $^{1} \cdot$ Nicolò Gerbino $^{1}$ • Nicola Caporaso ${ }^{1}$ - Antonio Rispo ${ }^{1}$

Published online: 19 September 2017

(C) Japanese Society of Gastroenterology 2017

Erratum to: J Gastroenterol

DOI 10.1007/s00535-017-1381-7

The correct name of the third author should be "Anna Testa", and not "Testa Anna" as given in the original publication of the article.

The original article was corrected.

The online version of the original article can be found under doi:10. 1007/s00535-017-1381-7.

Nicola Imperatore

nicola.imperatore@alice.it

1 Gastroenterology, Department of Clinical Medicine and

Surgery, School of Medicine "Federico II" of Naples, Via S.

Pansini 5, 80131 Naples, Italy

2 Hepatology Unit, AORN Cardarelli, Naples, Italy 